\title{
Brivudine Phosphoramidate
}

National Cancer Institute

\section{Source}

National Cancer Institute. Brivudine Phosphoramidate. NCI Thesaurus. Code C1882.

A small molecule phosphoramidate derivative of (E)-5-(2-bromovinyl)-2'-deoxyuridine

(BVdU) with potential antineoplastic activity. Selectively active ag ainst tumor cells expressing high levels of thymidylate synthase (TS), brivudine is converted intracellularly by TS to bromovinyldeoxyuridine monophosphate (BVdUMP) which competes with the natural substrate, deoxyuridine monophosphate, for binding to TS. Unlike TS inhibitors, this agent is a reversible substrate for TS catalysis. Thus, TS retains activity and converts BVdUMP into cytotoxic metabolites. As key enzyme in the de novo synthesis of dT MP, TS is an enzyme critical to DNA biosynthesis and is overexpressed in many solid tumors. 